Brit. J. prev. soc. Med. (1975), 29, 151-156

\title{
Relationship between month of birth and month of death in the elderly
}

\author{
MICHAEL ALDERSON \\ Medical Information Unit, Wessex Regional Health Authority, \\ 'Highcroft', Romsey Road, Winchester, Hampshire SO22 5DH
}

\begin{abstract}
Alderson, M. (1975). British Journal of Preventive and Social Medicine, 29, 151-156. Relationship between month of birth and month of death in the elderly. A special analysis of mortality data for England and Wales for 1972 has been used to examine the relationship between month of birth and month of death. For persons 75 and over in eight subgroups (by sex and marital status) there was a consistent trend in deaths with an excess in the birth month and the following three months. This excess was of the order of only $1 \%$ of all deaths in the year but statistically significant for each subgroup. The method of analysis was adjusted for the nonsynchronous monthly variation in births and deaths, but a systematic error in recording the month of birth could not be excluded.

A wide range of studies on the relationship between stress, morbidity, and mortality are briefly reviewed; it is suggested that in the elderly a birthday may in some subtle way influence the general morale of an individual. Further studies have been planned to test whether 'birthday stress' is a realistic explanation, or if a number of other hypotheses need to be invoked.
\end{abstract}

Ten years ago when involved in a World Health Organization study of the cause of adult mortality, the author was impressed by the frequency with which elderly adults appeared to have died in the month or two following the month of their birth. Though a number of subtle factors have been associated with variation in morbidity and mortality (see discussion) there appears to be no clearly documented relationship between month of birth and month of death of adults. This study set out to examine this issue, using national mortality data.

\section{METHOD}

A special analysis was obtained from the Office of Population Censuses and Surveys of the mortality data for England and Wales for 1972, tabulating month of birth and month of death, for both sexes under four categories of marital status (single, married, widowed, and other). The intention was to examine material for the elderly, and tables were prepared for persons aged 65 to 74, and 75 and over.

The number of births varies from month to month throughout the year, but in any given year there are more deaths in the winter months. To remove the effect of season on numbers of births and numbers of deaths, the counts of deaths were aggregated for each of the 12 tabulated months of birth by month of death centred around birth month. This provided a distribution of deaths occurring from the fifth month before the birth month up to the sixth month after the birth month. It was then possible to examine the distribution of observed deaths and the variation between the observed and expected number of deaths month by month.

\section{RESULTS}

There were 261226 deaths of persons aged 75 and over; but the month of birth was not known for $6162(2.3 \%)$ of them, so these were excluded from the analysis. Table I presents the difference between the observed and expected number of deaths in relation to the month of birth for men and women aged 75 and over, according to marital status. It can be seen that there is a deficiency of observed deaths in the months preceding the birth month, 
TABLE I

DIFFERENCE BETWEEN OBSERVED AND EXPECTED NUMBER OF DEATHS IN RELATION TO MONTH OF BIRTH, FOR MEN AND WOMEN AGED 75 AND OVER BY MARITAL STATUS, ENGLAND AND WALES, 1972

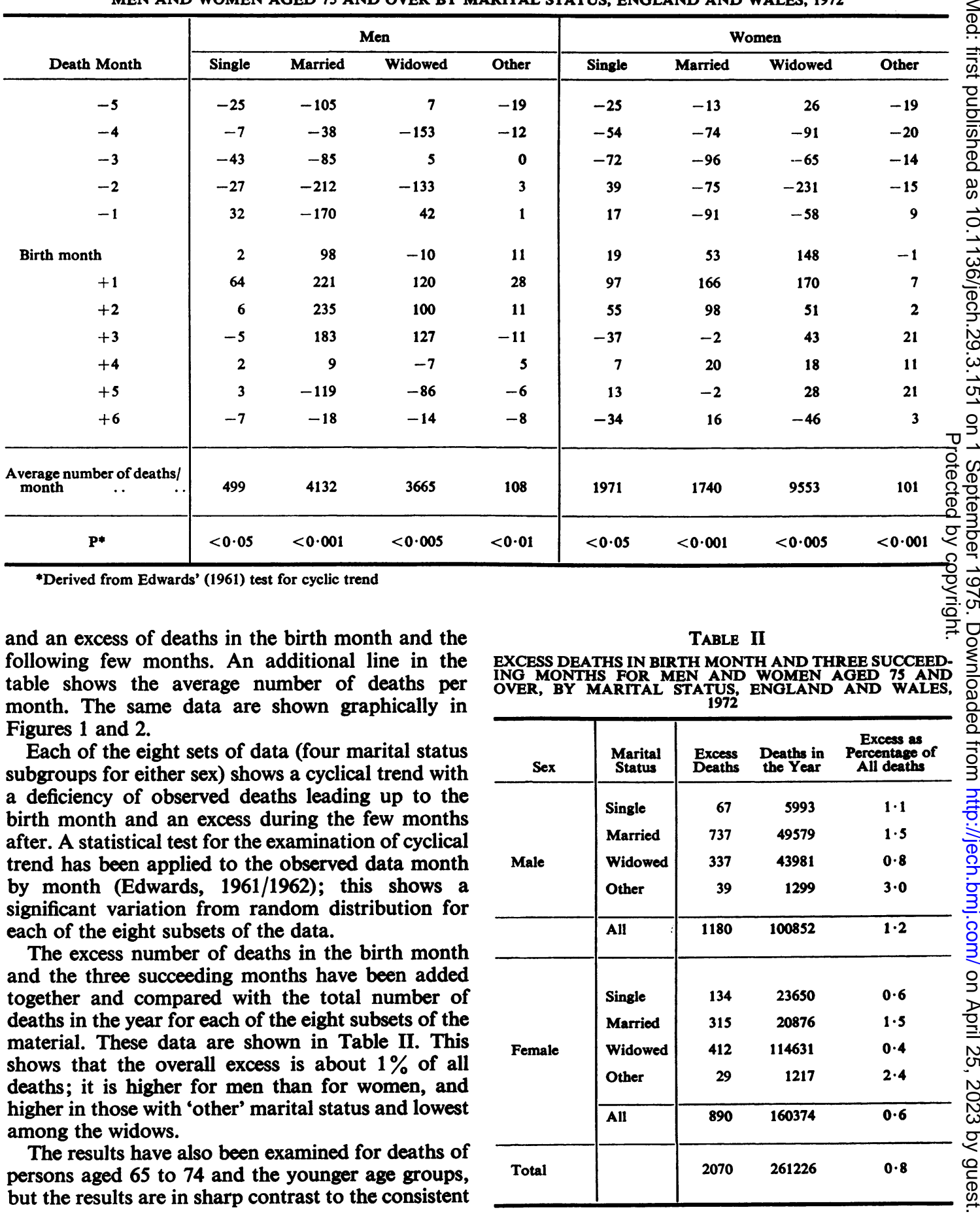




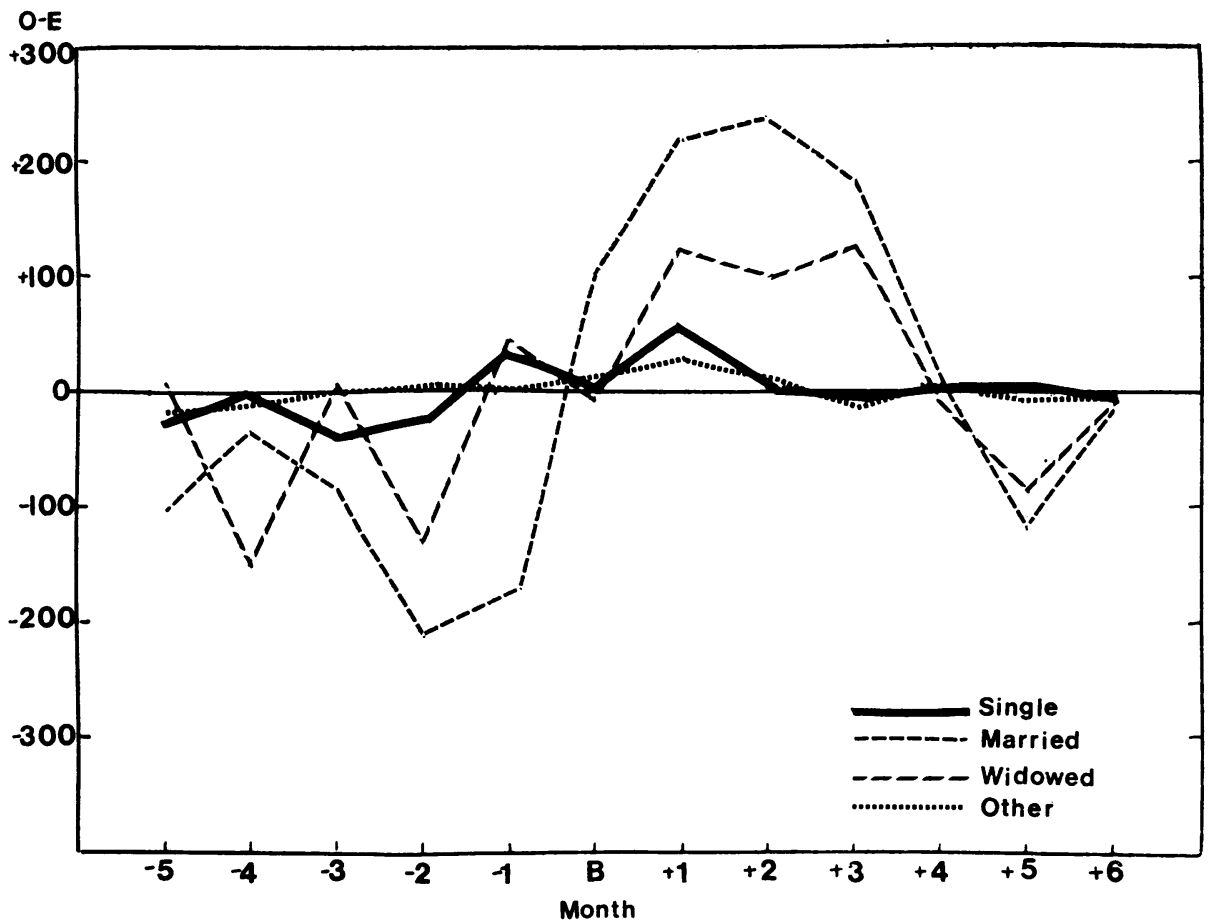

FIG. 1. Variation in observed minus expected deaths for men over $\mathbf{7 4}$, by months in relation to birth month and marital status, England and Wales 1972.

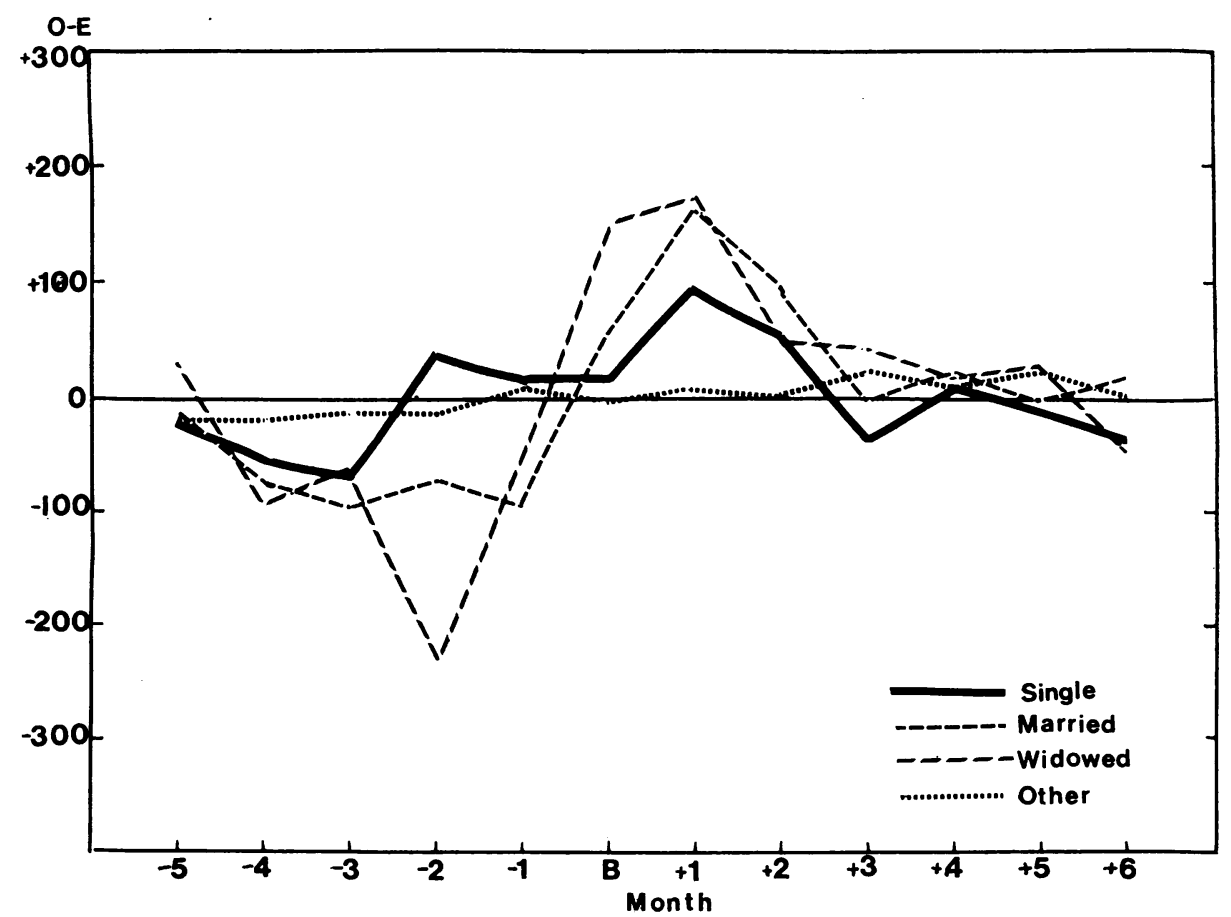

Fig. 2. Variation in observed minus expected deaths for women over $\mathbf{7 4}$, by months in relation to birth month and marital status, England and Wales 1972. 
picture presented here. There is no suggestion of an excess of deaths following the month of birth at younger ages; analysis showed nothing other than random fluctuation.*

\section{Discussion}

An examination of national morbidity data to check whether there was an association between the month of birth and the month of death among the elderly shows a consistent picture for eight subgroups for those aged 75 who died in England or Wales during 1972. Though the variation between observed and expected deaths in the subgroups examined is only about $1 \%$ of the average monthly number of deaths, the trend in each of the sets is consistent and statistically significant when tested for cyclic trend. This suggests that the finding is not therefore a statistical quirk. The method of analysis was adjusted for the non-synchronous monthly variation in births and deaths, but a systematic error in recording the month of birth could not be excluded in these data; a further study of this is in progress.

A number of authors (Young, Benjamin, and Wallis, 1963; Rees and Lutkins, 1967; Parkes, Benjamin, and Fitzgerald, 1969) have shown that there is increased mortality among widowers; these studies showed that mortality was particularly high in the six months following bereavement. The Registrar General (1971) has produced tables showing mortality rates by cause, age, and marital status indicating those high in the widowed. Other studies (Stein and Susser, 1969; Parkes, 1964) suggested that bereavement may be a causative factor in the development of mental illness. MacMahon and Pugh (1965) studied a sample of widows who had committed suicide and a matched widowed sample who had died from other causes. Compared with deaths from other causes, deaths from suicide were clustered in the first four years of widowhood, particularly the first year. In a study of a small number of people who were bereaved due to suicide, Shepherd and Barraclough (1974) found no significant difference in mortality compared with those widowed from other causes. Bunch and Barraclough (1971) showed that more than the expected number of suicides killed themselves at a time near to the anniversary of a parent's death. There is a statistical excess of admissions to psychiatric hospital among persons the same age as that at which their parents died, or when their children reach the age the patient was when their parent died (Hilgard, Newman, and Fisk, 1960; Hilgard and Newman, 1961).

\footnotetext{
*The tabulated results may be obtained on request from the author.
}

Bartlett (1932) has shown that there is a tendency to exaggerate the significance of events as a means of trying to come to terms with illness (effort after meaning). Brown and Birley (1970), using a stan-. dardized technique for questioning patients with mental illness, suggested that both schizophrenic $-\overrightarrow{0}$ patients and those with depressive illness report a $\frac{}{\circ}$ significant excess of exposure to stress in the period $\overline{\bar{\omega}}$ preceding development of illness. They describe $\widetilde{\Phi}$ (Brown, Harris, and Peto, 1973) a statistical technique $\stackrel{\circ}{\circ}$ for differentiating those effects that precipitate an ${ }^{\infty}$ illness and those which have a formative effect, and $\overrightarrow{0}$ suggest that certain life events have a formative $\vec{\longrightarrow}$ effect in depressives and a triggering effect on ${ }_{\sigma}$ schizophrenic disorders. Beck and Worthen (1972) also showed a precipitative effect of certain life crises $\stackrel{\bigcirc}{-}$ on depressive illness, but not for schizophrenia; if Chester (1971) showed that a sample of women $\dot{\omega}$ petitioners for divorce experienced deterioration of $\vec{G}$ health with symptoms presumptively related to stress. An excess incidence of mental illness is known to follow parturition (Paffenbarger, 1964) ang hysterectomy (Barker 1968; Richards, 1973).

For many years it has been suggested that 'stres? can be related to a range of physical disorders. Davies $\frac{\mathbb{D}}{3}$ and Wilson (1937) found that patients with peptic ulcers had a significant excess of preceding stressfigl events compared with a control sample of herni patients; a statistically significant rise was reporta in the number of perforations in the London are about the time of the blitz (Spicer, Stewart, and Winser, 1944). Rosenman et al., (1970) developed a technique for measuring an individual's reaction to stress; in a follow-up study they observed a signifi- $\stackrel{\odot}{\complement}$ cantly increased rate of coronary heart disease $\overrightarrow{\vec{A}}$ associated with a behaviour pattern that was $\frac{9}{3}$ independent of other risk factors. A number of other studies (Wardwell and Bahnson, 1973; Perlman et al., 1971 ; Eastwood and Trevelyan, $1971 ;$ Rahe et al., 1974) indicate that there is a link $\stackrel{\circ}{?}$ between reaction to stress and heart disease. Burns and Howell (1969) found that chronic bronchitics 3 . with disproportionate breathlessness reported exposure to psychogenic stress more frequently than control bronchitics. Kasl and Cobb (1969) suggested $\circ$ that there is a relationship between the development of arthritis and indicators of stress in the social $\frac{7}{8}$ setting of the patient, his marriage, or his parents' marriage. It was reported (Jones, MacDonald, and $\mathrm{N}$ Breslow, 1958) that patients with carcinoma of the $N$ cervix had been more consistently exposed to stressful conditions than had control subjects; a further case-control study (Graham et al., 1971) failed to detect any difference between cases and $\frac{0}{C}$ controls for a range of measures of social trauma. 
Other studies indicate a relationship between stress and the onset of acute closed-angle glaucoma (Cohen and Hajioff, 1972) and the incidence of streptococcal throats (Meyer and Haggerty, 1962).

Traditional folk lore ascribes sudden death to emotional shock; Engel (1971) described 170 examples collected over a six-year period, where a precipitating life situation had been followed by sudden death. It was stressed (Elkinton, 1971) that such a report was not a scientific demonstration of cause and effect but a clearly labelled hypothesis that requires testing for specific answers. Sargant (1973) has reviewed the relationship between battle stress and forms of possession; he and also Milton (1973) discuss death from fear and self-willed death.

There does not appear to be a clearly documented study which indicates that the month of birth could be included as a 'stress' factor. It is conceivable that to an elderly person a birthday acts as a reminder that he is growing older, and in some subtle way this may influence the general morale of the individual. The effect that has been observed in this study is only a minor one, being associated with about $1 \%$ excess of deaths in the four months following the birth month. The data are, however, another pointer to the subtle range of factors that influence morbidity and mortality. Analysis of material such as this obviously has no direct application but adds a little to the understanding of the influence of stress.

A relatively simple analysis of national material was planned merely to check the hypothesis that there was an association between month of birth and month of death in the elderly. This appears to be so from the data presented here, but a more detailed analysis of national material is required. In particular, checks must be carried out to exclude a systematic error in recording the month of birth. It would be useful to see whether there was a marked excess of certain causes of death; it would also be worth examining the data to see whether the passing of certain milestones is particularly associated with a peak in deaths (is the passage of threescore and ten or fourscore years associated with a greater peak than achieving the age of 77?). Such an exploration of national statistics can throw only limited light on the underlying mechanism that may be responsible for this observation. A case-control study would be required to elicit pointers to the variation in morale and other psychosocial parameters, triggered off by the passage of a birthday in the elderly. One of the difficulties in such a study would be the numbers of subjects required in order to identify a tenuous effect.
I am most grateful to $\operatorname{Dr} A$. M. Adelstein, who encouraged me to pursue this matter further and arranged for the special tabulation of mortality data to be produced. I have benefited from discussion with many, in particular Dr P. Sainsbury and colleagues in the Medical Information Unit.

Requests for reprints: Professor M. Alderson, Medical Information Unit, Wessex Regional Health Authority, 'Highcroft', Romsey Road, Winchester, Hampshire SO22 5DH.

\section{REFERENCES}

BARKER, M. G. (1968). Pschiatric illness after hysterectomy. Brit. med. J, 2, 91.

Bartlett, F. C. (1932). Remembering: A Study in Experimental and Social Psychology. Cambridge University Press, London.

BeCK, J. C. and WoRthen, K. (1972). Precipitating stress, crisis theory, and hospitalization in schizophrenia and depression. Arch. gen. Psychiat., 26, 123.

Brown, G. W. and BirLey, J. L. T. (1970). Social precipitants of severe psychiatric disorders, p. 323. In Psychiatric Epidemiology, edited by E. H. Hare, and J. K. Wing. Oxford University Press, London. Published for the Nuffield Provincial Hospitals Trust.

- Harris, T. O., and Peto, J. (1973). Life events and psychiatric disorders, part 2: Nature of causal link. Psychol. Med., 3, 159.

BunCH, J. and BarRaClough, B. (1971). The influence of parental death anniversaries upon suicide dates. Brit. J. psychiat. soc. Work, 118, 621.

BuRNS, B. H. and Howell, J. B. L. (1969). Disproportionately severe breathlessness in chronic bronchitis. Quart. J. Med., 38, 277.

Chester, R. (1971). Health and marriage breakdown: Experience of a sample of divorced women. Brit. $J$. prev. soc. Med., 25, 231.

Cohen, S. I. and Hajiof, J. (1972). Life events and the onset of acute closed-angle glaucoma. J. psychosom. Res., 16, 335.

DAvies, D. T. and Wilson, A. T. M. (1937). Observations on the life-history of chronic peptic ulcer. Lancet, 2 , 1353.

Eastwood, M. R. and Trevelyan, H. (1971). Stress and coronary heart disease. J. psychosom. Res., 15, 289.

EDWARDS, J. H. (1961/1962). The recognition and estimation of cyclic trends. Ann. hum. Genet., 25, 83.

Elkinton, J. R. (1971). Scared to death? Ann. intern. Med., 74, 789.

ENGEL, G. L. (1971). Sudden and rapid death during psychological stress, folklore, or folkwisdom? Ann. intern. Med., 74, 771.

Graham, S., Snell, L. M., Graham, J. B., and Ford, L. (1971). Social trauma in the epidemiology of cancer of the cervix. J. chron. Dis., 24, 711. 
Hilgard, J. R., Newman, M. F., and Fisk, F. (1960). Strength of adult ego following childhood bereavement. Amer. J. Orthopsychiat., 30, 788.

- and (1961). Evidence for functional genesis in mental illness: Schizophrenia, depressive psychoses and psychoneuroses. J. nerv. ment. Dis., 132, 3.

Jones, E. G., MacDonald, I., and BReslow, L. (1958). A study of epidemiologic factors in carcinoma of the uterine cervix. Amer. J. Obstet. Gynec., 76, 1.

KASL, S. V. and CoBB, S. (1969). Intrafamilial transmission of rheumatoid arthritis-VI. Association of rheumatoid arthritis with several types of status inconsistency. J. chron. Dis., 22, 259.

MacMahon, B. and Pugh, T. F. (1965). Suicide in the widowed. Amer. J. Epidem., 81, 23.

MEYER, R. J. and HAGGeRTY, R. J. (1962). Streptococcal infections in families-factors altering individual susceptibility. Pediatrics, 29, 539.

Milton, G. W. (1973). Self-willed death or the bonepointing syndrome. Lancet, 1, 1435.

Paffenbarger, R. S. (1964). Epidemiological aspects of parapartum mental illness. Brit. J. prev. soc. Med., 18, 189.

Parkes, C. M. (1964). Recent bereavement as a cause of mental illness. Brit. J. psychiat. soc. Work, 110, 198.

- Benjamin, B., and Fitzgerald, R. G. (1969). Broken heart: a statistical study of increased mortality among widowers. Brit. med. J., 1, 740.

Perlman, L. V., Ferguson, S., Bergum, K., Isenberg, E. L., and Hammarsten, J. F. (1971). Precipitation of congestive heartfailure: social and emotional factors. Ann. intern. Med., 75, 1.
Rahe, R., Romo, M., Bennett, L., and Siltanen, P. (1974). Recent life changes, myocardial infarction and abrupt coronary death. Arch. intern. Med., 133, 221.

ReEs, W. D. and Lutkins, S. G. (1967). Mortality of bereavement. Brit. med. J., 4, 13.

Registrar General (1971). Statistical review for England and Wales for the year 1967 part III, commentary, p. 130. HMSO, London.

RICHARDS, D. H. (1973). Depression after hysterectomy. Lancet, 2, 430.

Rosenman, R. H., Friedman, M., Straus, R., Jenkins, C. D., ZYZANSKI, S. J., and WURM, M. (1970).Coronary heart disease in the western collaborative group study: a follow-up experience of four and a half years. J. chron. Dis., 23, 173.

Sargant, W. (1973). The Mind Possessed-A Physiology of Possession, Mysticism and Faith Healing. Heinemann, London.

ShePherd, D. and BARRAClOUgh, B. M. (1974). The aftermath of suicide. Brit. med. J., 2, 600.

SPICER, C. C., Stewart, D. N., and Winser, D. M. de RT (1944). Perforated peptic ulcer during the period of $\mathcal{D}$ heavy air-raids. Lancet, 1, 14.

STEIN, Z. and SusSER, M. (1969). Widowhood and menta illness. Brit. J. prev. soc. Med., 23, 106.

WARDWELL, W. I. and BAHNSON, C. B. (1973). Behavioura variables and myocardial infarction in the sout eastern Connecticut heart study. J. chron. Dis., 26, 447.

Young, M., Benjamin, B., and Wallis, C. (1963). The mortality of widowers. Lancet 2, 454. 